\title{
NEW NATURAL DYES DEVELOPMENT: Caesalpinia Sappan L.-Curcuma Longa BLENDED DYES
}

\author{
N. Kusumawati ${ }^{1, *}$, Samik ${ }^{1}$, A.B. Santoso ${ }^{2}$ and S. Muslim ${ }^{2}$ \\ ${ }^{1}$ Department of Chemistry, Faculty of Math and Science/Universitas Negeri Surabaya, Surabaya- \\ 60231, (East Java) Indonesia \\ ${ }^{2}$ Department of Electrical Engineering, Faculty of Engineering/Universitas Negeri Surabaya, \\ Surabaya-60231, (East Java) Indonesia \\ *E-mail : nkusumawati82@yahoo.com
}

\begin{abstract}
This study has focused on the natural dye extraction from a combination of Caesalpinia sappan L. (CSL) bark and Curcuma longa (CL) bulbs and evaluation of the physicochemical characteristics and performance (color intensity and fastness). To enrich the shades, the CSL-CL extracts were prepared by water solvent extraction using three dye compositions (75\% CSL/25\% CL; 50\% CSL/50\% CL and 25\% CSL/75\% CL) and three fixers (iron (II) sulfate, alum, and calcium oxide). To optimize the interactions between fabric and dye to produce high intensity and fastness, two preparation stages were performed before dyeing, i.e. washing using turkey red oil (TRO) and mordanting using alum and soda ash. UV spectral analysis shows variations in the maximum adsorption wavelength triggered by differences in dye composition. In line with this, the dyeing results also show the shades variation resulting from different types of fixers. From the CieLab coordinate, CL dye which is applied with calcium oxide fixer has produced the brightest color (highest $\mathrm{L}^{*}$ ) with the appearance of the least reddish (highest $\mathrm{a}^{*}$ ) and most yellowish (highest $b^{*}$ ) color compared to other compositions and fixers.
\end{abstract}

Keywords: Natural Dyes, Caesalpinia Sappan L., Bark, Curcuma Longa, Bulb

(C) RASĀYAN. All rights reserved

\section{INTRODUCTION}

Dyeing with natural dyes has been done since ancient times and has many developments in the present time. However, the appearance of synthetic dyes in the nineteenth century has been a major blow to the existence of these dyes. This condition is exacerbated by the lack of availability of dye materials due to the lack of organized manufacturing, raw material characteristics, and unstandardized manufacturing procedures, as well as the complexity of stages in the natural dyes utilization. ${ }^{1-5}$ This condition has triggered the dominance of synthetic dyes that began to be discovered in the 19th century. Various shades and raw materials abundance is the main cause of synthetic dye dominance ever since. In its development, synthetic dyes are known to be unbreakable, can cause skin and lung disease ${ }^{6-8}$ and are carcinogenic (causing cancer). ${ }^{9-10}$ This makes a large number of developed countries reluctant to apply, sell, and import non-eco-friendly dye products from other countries. ${ }^{11}$ Thus, the fashion trend of the world is slowly beginning to take back the utilization of natural dyes in the fabrication process of textiles. Today, natural dyes with abundant raw material availability in the surrounding environment, its biocompatibility, low toxicity, and eco-friendly properties, gained worldwide popularity for textile applications. ${ }^{12-14}$

Natural dyes are obtained from the extraction of various parts of a specific plant, ${ }^{15-17}$ such as roots, rhizomes, bark, seeds, leaves, flowers or fruits. The part of the specific plant in question is like bark on Caesalpinia Sappan L. (Brazilwood) ${ }^{18}$ and turmeric bulbs. In Brazilwood, the primary source of color comes from the red chromophore structure of water-soluble brazilin flavonoid molecules. The findings on the research report the acquisition of pure brazilin- $\mathrm{Al}^{3+}$ complexes from Brazilwood bark extraction. ${ }^{19-22}$ The results of the UV-Vis spectroscopy and $\mu$-spectroflourimetry analysis reported the maximum absorption, excitation, and emission wavelengths of the respective chromophores, at 446, 475 and 536

Rasayan J. Chem., 13(2), 991-999(2020)

http://dx.doi.org/10.31788/RJC.2020.1325410

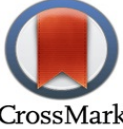


$\mathrm{nm}$, respectively, which subsequently experienced a bathochromic shift at 540,548 , and $560 \mathrm{~nm}$ when deprotonated. The second bathochromic shift of the maximum absorption, excitation, and emission wavelengths is detected when these chromophores form complexes with $\mathrm{Al}^{3+}$, each of which takes place at 510,520 , and $585 \mathrm{~nm}$.

Several advantages of Brazilwood's red chromophore do not necessarily provide a guarantee of sustainable use of dyes in the future. The level of saturation of the public against the same color and high dynamics in the fashion and interior trends of the world that often involve color change are two determinants of the sustainability of specific color utilization in various industries. Therefore, it is important to continue to develop the dyeing by utilizing various local potentials in the surrounding environment that produce variants of shades, high color strength, and fastness. The exploration and standardization of dyeing using natural dyes are expected to ensure the sustainability of the eco-friendly dyes use. One way that can be done to expand the shades of Brazilwood color is to blend using another dye that has a different chromophore and can produce dyeing with high color strength and fastness.

Curcumin is one of some natural dyes that can produce high color strength and fastness. This compound is the best known natural yellow color producer. This dye is produced from the extraction of the Curcuma longa $\mathrm{L}$ root and bulb. It contains the main active compound that called curcumin, which was also known as Natural Yellow 3 (C I 75300) as well as a small amount of demethoxycurcumin and bisdemethoxycurcumin. ${ }^{23-24}$ The research reported that curcumin is not only able to dye the fibers in bright yellow shades but also be able to provide additional functional properties including antibacterial and antioxidant activity. ${ }^{25-26} \mathrm{Besides,}$ this dye is also known for its anti-carcinogenic, anti-perceptive, and anticancer properties. ${ }^{27}$ Thus, brazilin and curcumin blending will not only expand the shades but also produce dyeing with high color strength and fastness as well as superior functional properties that bring many positive effects to its users.

The brazilin molecule has three hydroxyl groups attached to each of the benzene rings, while the curcumin molecule has two hydroxyl groups on each of the benzene rings. The hydroxyl functional groups both become highly reactive under alkaline conditions. ${ }^{28}$ However, the dominance of the same functional groups on cotton fibers has made it difficult to establish reactions and interactions with brazilin and curcumin. In this case, the conversion procedure of water-soluble dyes to water-insoluble dyes through mordant usage is predicted to result in increased color stability. The positive charge present in a metal complex with more than one valence commonly used as mordant serves as a bridge for reaction and interaction between the negative charges of hydroxyl groups of fibers with a negative charge of brazilin and curcumin molecules used in dyeing. One of the most used mordant for example is an alum (aluminum hydrate or aluminum sulfate). In this study, alum was applied in a dyeing procedure with a premordanting method, where the mordant application was performed before the fibers were dyed. This condition will produce three bonds, namely cellulose-Al, Al-brazilin and Al-curcumin. Several previous studies have reported that Al-brazilin has a high light-fastness property. ${ }^{29-30}$ Increased fastness is also done through the utilization of iron (II) sulfate, alum and calcium oxide as a color-locking agent. The existence of this color-locking agent will prevent any further reaction/interaction of the dye on the fibers. However, it should be noted that the presence of specific chromophore and auxochrome groups which may be contained in the fixer has the potential to cause a change in the shades formed on the fiber.

\section{EXPERIMENTAL}

\section{Material and Methods}

Brazilwood bark is bought from herbal medicine shop UD. DWI Jaya (Surabaya, Indonesia), turmeric is bought from traditional market PT. Lion Superindo (Surabaya, Indonesia). Before applied to dye, both materials go through a drying process at $50{ }^{\circ} \mathrm{C}$ to get a water content below $10 \%$. The distilled water used as a solvent for the extraction of brazilin and curcumin is obtained from AMDK Universitas Negeri Surabaya (Surabaya, Indonesia). To minimize the presence of contaminants that may inhibit the reaction between fibers and mordant, cotton fibers are treated using Turkish Red Oil (TRO) (strength 70\%) purchased from CV. Dunia Kimia (Surabaya, Indonesia), alum or aluminum sulfate $\left[\mathrm{Al}_{2}\left(\mathrm{SO}_{4}\right)_{3} \cdot 18 \mathrm{H}_{2} \mathrm{O}\right.$ ] (purity $\geq 17 \%$ ) purchased from PT. Brataco Chemistry (Surabaya, Indonesia) which has a dual function, that is as compound bridging the occurrence of reactions between fibers and dyes along with soda ash 
RASĀYAN J. Chem.

Vol. 13 | No. 2 |991 - 999| April - June | 2020

$\left(\mathrm{Na}_{2} \mathrm{CO}_{3}\right)$ (purity $\geq 48 \%$ ) purchased from $\mathrm{CV}$. Water (Surabaya, Indonesia) and as one of the fixers applied after the dyeing. While the other fixers used are iron (II) sulfate $\left(\mathrm{FeSO}_{4} \cdot 7 \mathrm{H}_{2} \mathrm{O}\right)$ (density 2,84 $\left.\mathrm{g} / \mathrm{cm}^{3}\right)$ and calcium oxide $(\mathrm{CaO})(\geq 90 \%)$ each purchased from PT. Nusa Indah Megah (Surabaya, Indonesia) and Mitra Water (Surabaya, Indonesia).

\section{Washing}

In this study, washing was done to minimize contaminants that have the potential to inhibit the formation of interactions between fibers, either with alum mordant or with dye. Increased color strength and fastness were conducted by immersion of 2.57 grams of fiber in 2 grams/liter TRO $(6 \mathrm{~h})$. To remove the mordant residue which does not react with the fibers, it is rinsed using distilled water for 3 times. This washing procedure was ended by drying fiber in the open air $(24 \mathrm{~h}) .^{14}$

\section{Mordanting}

To improve the reactivity between fibers with brazilin and curcumin dyes, mordanting treatment with alum and soda ash was done. The mordant solution was prepared from 8 grams of alum and 2 grams of soda ash in 1 liter of distilled water. To optimize the solution homogeneity, stirring was carried out with a magnetic stirrer for 5 minutes. The mordant solution is formed, heated to boiling and into it is added 2.57 grams of fiber. Immersion process of fiber in mordant solution with temperature $100{ }^{\circ} \mathrm{C}$ is done for $1 \mathrm{~h}$. To obtain an optimum reaction between fibers and mordant, the immersion was carried out for $24 \mathrm{~h}$ without further heating. To remove residual mordant remaining on the fabric, fibers are rinsed three times without being squeezed, dried and then ironed to obtain a uniform fiber orientation. ${ }^{14}$

\section{Dyeing}

The dyeing procedure with Brazilwood bark and Curcuma Longa bulb extract was performed using operational conditions as presented in Table-1 and the blending composition as shown in Table-2. ${ }^{14}$

\begin{tabular}{c|c|c}
\multicolumn{2}{c}{ Table-1: The Dyeing Process Operational Conditions } \\
\hline No & \multicolumn{2}{|c}{ Operational Conditions } \\
\hline 1 & Material : liquor & $1 / 35(\mathrm{~g} / \mathrm{mL})$ \\
\hline 2 & Temperature & Ambient temperature \\
\hline 3 & Fiber weight & $0.85 \mathrm{~g}$ \\
\hline 4 & Dyeing time & $50 \mathrm{~min}$ \\
\hline
\end{tabular}

Table-2: The Blending Compositions

\begin{tabular}{c|c|c|c}
\hline \multirow{2}{*}{ No } & \multirow{2}{*}{$\begin{array}{c}\text { Type of } \\
\text { Blending }\end{array}$} & \multicolumn{2}{|c}{ Extract Compositions (\%) } \\
\cline { 3 - 4 } & Brazilwood bark & Curcuma longa \\
\hline 1 & BWB & 100 & 0 \\
\hline 2 & BWB/CL-1 & 75 & 25 \\
\hline 3 & BWB/CL-2 & 50 & 50 \\
\hline 4 & BWB/CL-3 & 25 & 75 \\
\hline 5 & CL & 0 & 100 \\
\hline
\end{tabular}

\section{Fixation}

The color-locking process in fibers is carried out using three fixers, including iron (II) sulfate, alum, and calcium oxide. This process will decrease the reactivity of the dye on the fibers, thereby reducing the potential for color loss. Each fixer solution was prepared by dissolving 50 grams of fixer in 1 liter of distilled water. The solution was allowed to stand for 24 hours to get a transparent part. The fixation step is carried out by immersion of 0.85 grams of fibers which have gone through the dyeing within $30 \mathrm{~mL}$ of fixer solution for 10 minutes. The fixation is terminated by rinsing the fibers using distilled water (three times, each flushing with $100 \mathrm{~mL}$ rinse volume) and drying in the open air. ${ }^{14}$

\section{Characterization}

Some analyzes were performed to characterize the presence of brazilin and curcumin dyes in the Brazilwood bark and Curcuma longa bulbs extract, including the analysis of the maximum wavelength 
RASĀYAN J. Chem.

Vol. 13 | No. 2 |991 - 999| April - June | 2020

$\left(\lambda_{\max }\right)$ of each dye extract with UV-Visible Spectrophotometer (Pharmaspec UV-1700, Shimadzu, Kyoto, Japan). This analysis was performed to determine the dominant pigment in each dye extracts. The CieLab coordinates $\left(\mathrm{L}^{*}, \mathrm{a}^{*}, \mathrm{~b}^{*}\right)$ of each dye extract were analyzed to determine the color difference, including the color brightness expressed by the notation of $L^{*}(0$ (black) - 100 (white)), the tendency of the formation of greenish or reddish color expressed by the notation of a* (-100 (greenish) - 100 (reddish)) and a bluish or yellowish color tendency expressed by the notation of $b^{*}(-100$ (bluish) -100 (yellowish)). This analysis was performed using a spectrophotometer (Tintometre, Lovibond PFX 195 V 3.2, Amesbury, UK). Analysis of color strength and fastness was performed to evaluate the effect of blend composition and fixer on the color quality produced by brazilin, curcumin and the combination of both. Color strength can be evaluated using Diffuse Reflectant Ultraviolet (DRUV) Spectrophotometer (UV-2401-PC, Shimadzu, Kyoto, Japan) while fastness can be analyzed with staining scale. Particularly in the DRUV analysis, a lower reflectance percentage value indicates a higher color strength. ${ }^{14}$

\section{Washing}

\section{RESULTS AND DISCUSSION}

The purpose of the washing procedure is to minimize the presence of contaminants in fibers to optimize the reaction with mordant. Contaminants, especially those positively charged, have the potential to play the same role as mordant. However, most of these contaminants rely solely on physical interactions with the fibers so they are easily removed along with the washing process. This will automatically decrease the fastness. Besides, the presence of specific chromophores and auxochrome groups on the fibers may affect the outcome of the dyeing. Figure-1 illustrates the TRO's working mechanism in releasing contaminants from the fibers to the water.
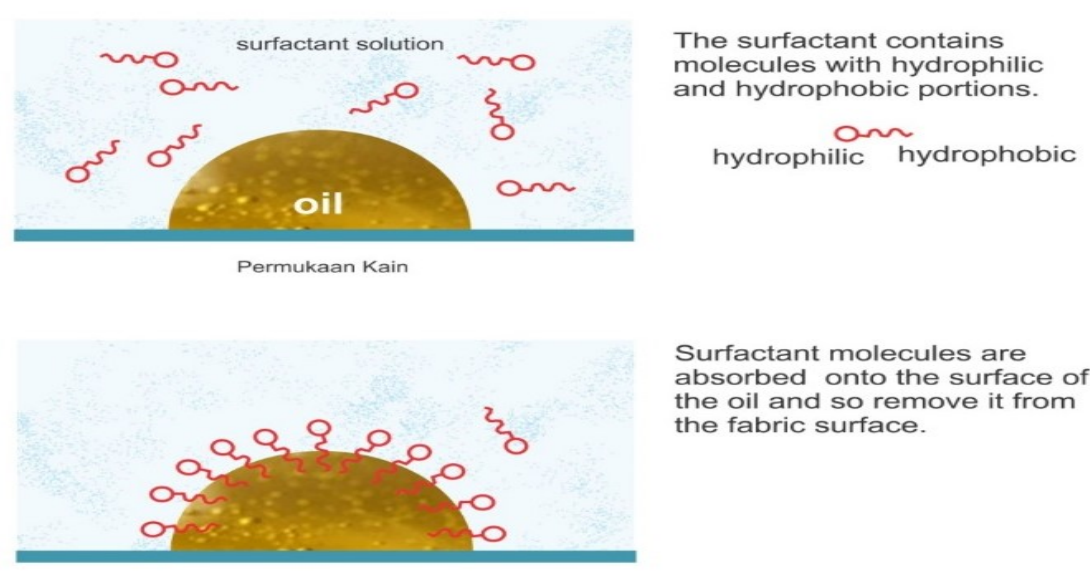

The surfactant contains molecules with hydrophilic and hydrophobic portions.

$$
\text { hydrophilic hydrophobic }
$$

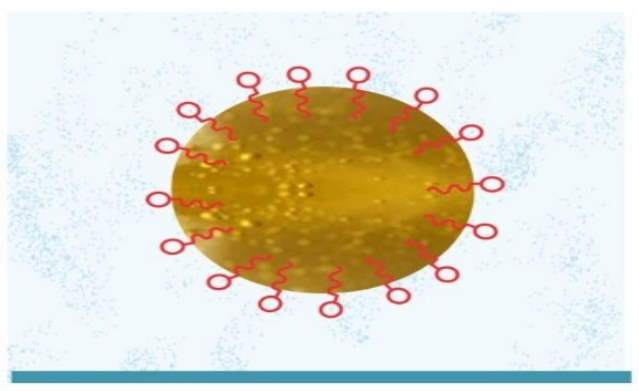

Surfactant molecules are absorbed onto the surface of the oil and so remove it from the fabric surface.

Fig.-1: TRO's Working Mechanism in the Washing Process

\section{Mordanting}

The surfactant molecules remain surrounding the oi once it has been removed, so helping to prevent its redeposition onto the cleaned surface.

The application of mordanting is intended to provide intermediaries or bridging the occurrence of reactions between the negative charge of the cotton hydroxyl group with the negative charge of the 
RASĀYAN J. Chem.

Vol. 13 | No. 2 |991 - 999| April - June | 2020

brazilin, curcumin, and combination of both. Figure-2 shows the reaction mechanism at the mordanting. Eliminating this stage from fibers dyeing will not completely remove the color from the fiber. The appearance of the color on the fibers in this condition is more triggered by the dye deposition on the surface and internal pores of the fibers. The appearance of colors like this is not beneficial because the dye becomes easily washed out, resulting in fastness reduction. All metal compounds that have a positive charge with more than one valence can be utilized as a mordanting agent. However, the utilization of metal compounds as a mordant must still pay attention to the negative impacts caused to both living things and the environment. For example, the use of chromium metal compounds having a positive charge with valences 5 and 6 , which has been widely used by the textile industry, has been shown to have adverse effects on living organisms due to its carcinogenic and environmental effects due to its nonbiodegradable nature. This is following what is reported by. ${ }^{31}$

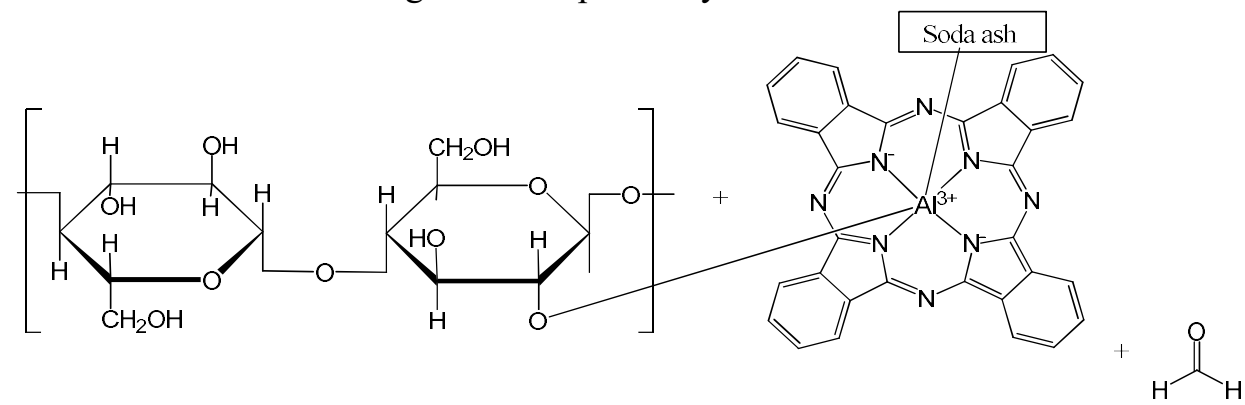

Fig.-2: The Reaction Mechanism at the Mordanting Stage Dyeing

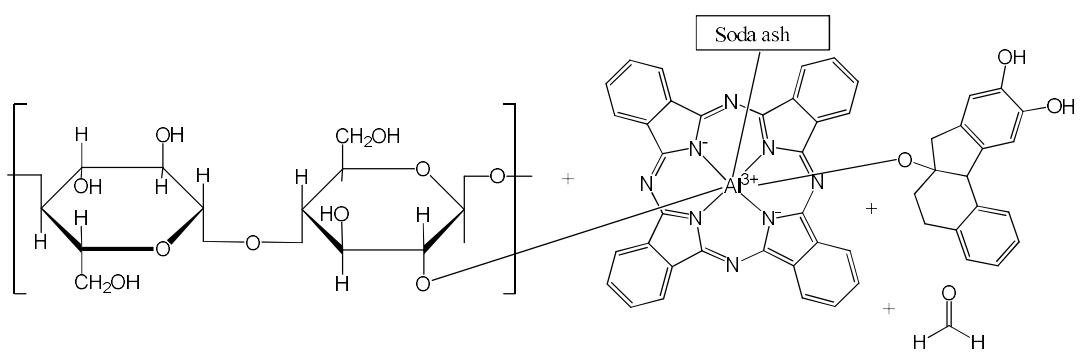

(a)

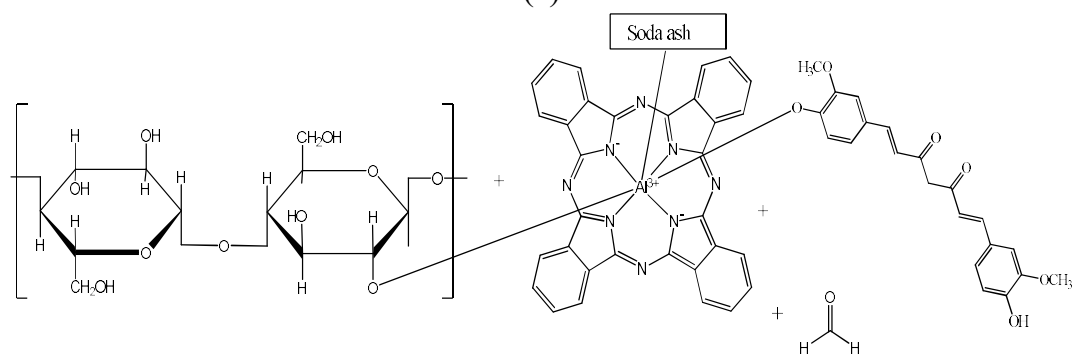

(b)

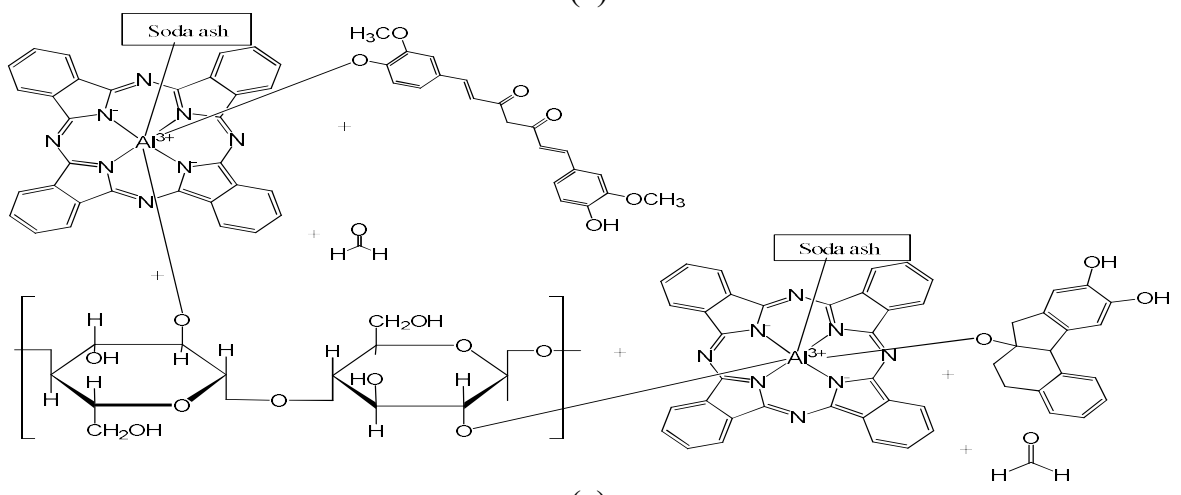

(c) 
RASĀYAN J. Chem.

Vol. 13 | No. 2 |991 - 999| April - June | 2020

Fig.-3: The Reaction Mechanism at the Dyeing Stage with (a) BWB; (b) CL; (C) Combination of Both Extracts ${ }^{22}$ The BWB, CL, and combination dyes are both prepared using water-solvent extraction and applied with different compositions and fixer (as shown in Table-2). The results of the dye extract analysis using UVVis spectrophotometry show the appearance of red color from BWB extract with maximum wavelength $538.57 \mathrm{~nm}$, rese color from BWB/CL-1 extract with maximum wavelength $538.50 \mathrm{~nm}$; coral color from BWB/CL-2 extract with maximum wavelength $538.49 \mathrm{~nm}$; orange color from BWB/CL-3 extract with maximum wavelength $440.30 \mathrm{~nm}$, and yellow color from the CL extract with the maximum wavelength $383.19 \mathrm{~nm}$. These results indicate that an increase in CL levels has resulted in a brighter yellow color. This is reinforced by the occurrence of hypsochromic or maximum wavelength shifts from BWB dye extracts in the lower direction. The predominance of the presence of $\mathrm{C}=\mathrm{C}$ and $\mathrm{C}=\mathrm{O}$ chromophores, as well as hydroxide $(\mathrm{OH})$ auxochromes typical of curcumin as elevated levels of CL dye extract, have decreased the wavelength region in which the dye extract absorbs electromagnetic waves optimally. Fig.3 shows the reaction mechanisms that occur in fiber dyeing using BWB, CL and a combination of both. The color intensity analysis performed using DRUV shows the color strength of BWB which is lower than CL. This condition is induced by the dominance of negatively charged functional groups $\left(\mathrm{HO}^{-} ; \mathrm{O}^{2-}\right.$ and $\mathrm{CH}_{3} \mathrm{O}^{-}$) on the curcumin compared to brazilin, thus causing more curcumin attached to the same conditions and composition of dyeing.

To determine the color differences that arise as a result of the increase in CL content in the dyes blend, it has been done an analysis using the colorimetric method which is expressed as CieLab coordinates. The results show that the brightness reaches its peak when used CL extract, which is reflected from the highest $\mathrm{L}^{*}$ value. This value gradually decreases with decreasing levels of CL in the blended dyes. In Table 1 has been present the CieLab coordinates for each dye extracts with different compositions. The results also show the highest $a^{*}$ in the BWB and $b^{*}$ in the CL dyes extract. The $a^{*}$ and $b^{*}$ values resulting from the dyeing using the BWB show that the brazilin has produced shades with the highest reddish and lowest yellowish.

Table-3: The CieLab Coordinate of the Dyes with a Different Composition

\begin{tabular}{|c|c|c|c|c|c|}
\hline \multirow{2}{*}{ No } & \multirow{2}{*}{$\begin{array}{l}\text { Type of } \\
\text { Blending }\end{array}$} & \multirow{2}{*}{$\begin{array}{c}\text { Color Intensity } \\
(\%)\end{array}$} & \multicolumn{3}{|c|}{ CieLab Coordinate $\left(\mathrm{L}^{*}, \mathrm{a}^{*}, \mathrm{~b}^{*}\right)$} \\
\hline & & & $\mathrm{L}^{*}$ & $\mathrm{a}^{*}$ & $\mathrm{~b}^{*}$ \\
\hline 1 & BWB & 95.99 & 47.34 & 19.02 & 6.97 \\
\hline 2 & BWB/CL-1 & 89.99 & 48.18 & 14.98 & 3.60 \\
\hline 3 & BWB/CL-2 & 82.74 & 52.99 & 15.66 & 5.12 \\
\hline 4 & $\mathrm{BWB} / \mathrm{CL}-3$ & 90.76 & 51.44 & 19.02 & 7.26 \\
\hline 5 & CL & 78.01 & 76.00 & 12.57 & 31.00 \\
\hline
\end{tabular}

\section{Fixation}

The different fixer application has resulted in the appearance of the significantly different shade. The dyeing ends with iron (II) sulfate fixation has produced a dark shade, while the alum and calcium oxide fixation, has resulted in brownish and bright shades. This color difference is due to the influence of the specific chromophores and auxochrome contained in each fixer. The different chromophores and auxochromes will determine the magnitude of electromagnetic wave absorption, the maximum wavelength and the electronic transition occurring. Figure-4 shows the reaction mechanism occurring in the fixation process.

To more detail evaluate the color difference resulting from the dyeing with a different fixer, a colorimetric analysis was performed. The CieLab coordinate shows the highest brightness (L*) from calcium oxide fixation and successively decreasing on the alum and iron (II) sulfate fixation. The alum fixation results highest reddish $\left(\mathrm{a}^{*}\right)$ and yellowish $\left(\mathrm{b}^{*}\right)$ shades, as shown in Table-4. This indicates that alum fixation results in an electronic transition at a maximum wavelength which is longer than the calcium oxide but shorter than iron (II) sulfate fixation. Compared to the dye composition effect, the different fixer effect shows that alum fixation indicates the occurrence of electronic transition at a longer wavelength. The same condition was found in the calcium oxide and iron (II) sulfate fixation results, where after the fixation, each of the resulting colors indicates an electronic transition at wavelengths that are also longer. Thus, it is clear that the presence of specific chromophores and auxochrome in each fixer used has a significant effect on the electronic transition and the final shades produced. 
RASĀYAN J. Chem.

Vol. 13 | No. 2 |991 - 999| April - June | 2020

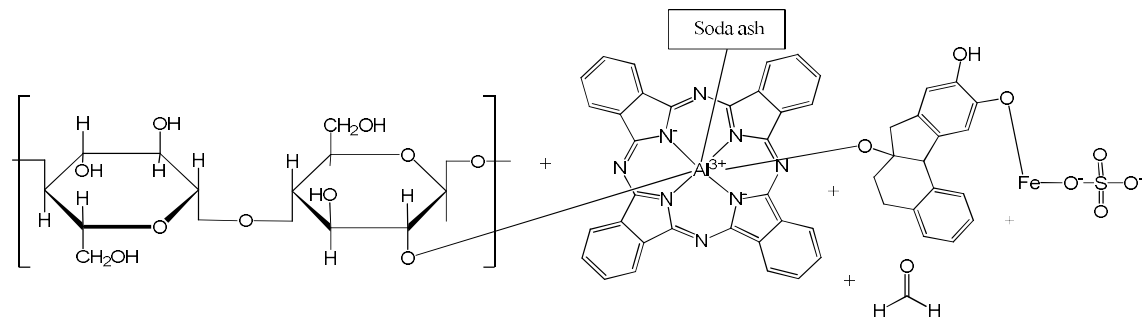

(a)

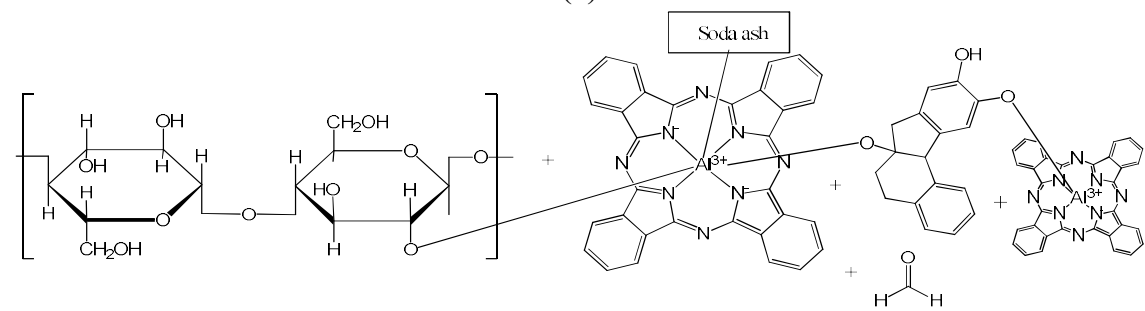

(b)

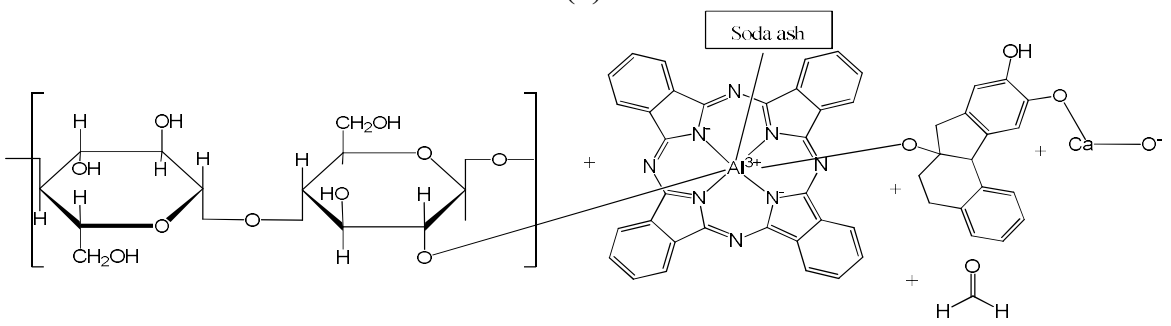

(c)

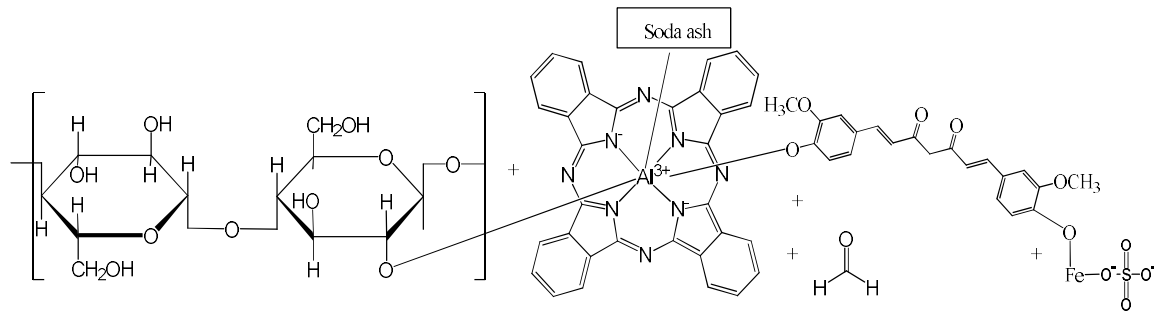

(d)

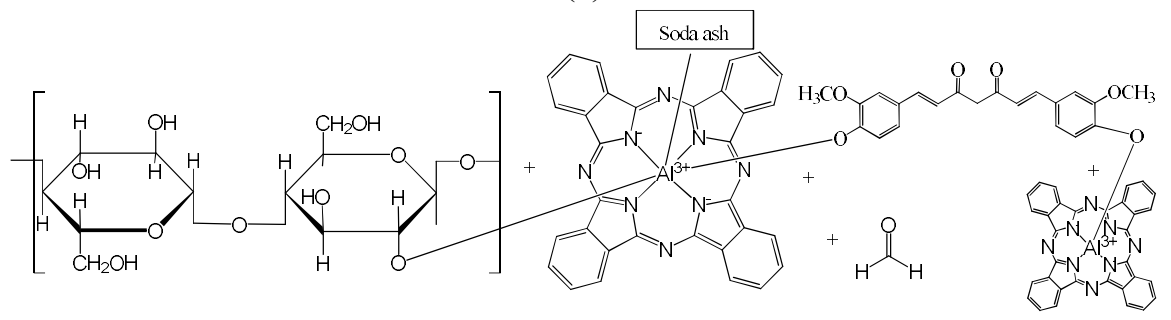

(e)

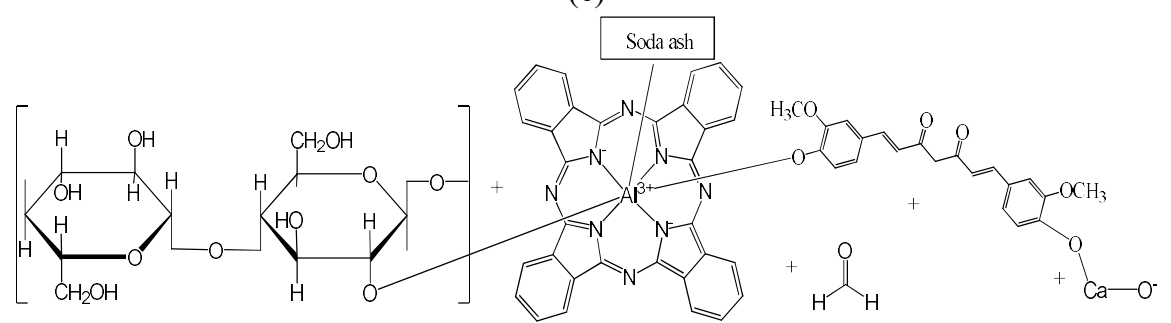

(f)

Fig.-4: The Reaction Mechanism at the Fixation: (a) Brazilin with Iron (II) Sulfate; (b) Brazilin with Alum; (c) Brazilin with Calcium Oxide; (d) Curcumin with Iron (II) Sulfate; (e) Curcumin with Alum; and (f) Curcumin with Calcium Oxide ${ }^{22}$ 
RASĀYAN J. Chem.

Vol. 13 | No. 2 |991 - 999| April - June | 2020

Table-4: The CieLab Coordinates of the Dyes with a Different Fixer Types

\begin{tabular}{|c|c|c|c|c|c|}
\hline \multirow{2}{*}{ No. } & \multirow{2}{*}{ Type of Blending } & \multirow{2}{*}{$\begin{array}{c}\text { Color Intensity } \\
(\%)\end{array}$} & \multicolumn{3}{|c|}{ CieLab Coordinates $\left(L^{*}, a^{*}, b^{*}\right)$} \\
\hline & & & $\mathrm{L}^{*}$ & $a^{*}$ & $\mathrm{~b}^{*}$ \\
\hline 1 & $\begin{array}{c}\text { BWB } \\
\text { (Iron (II) Sulfate) }\end{array}$ & 95.99 & 53.00 & 5.92 & 4.80 \\
\hline 2 & $\begin{array}{l}\text { BWB } \\
\text { (Alum) } \\
\end{array}$ & 93.21 & 54.49 & 26.40 & 12.70 \\
\hline 3 & $\begin{array}{c}\text { BWB } \\
\text { (Calcium Oxide) }\end{array}$ & 92.13 & 67.49 & 22.43 & 12.64 \\
\hline 4 & $\begin{array}{c}\text { BWB/CL-2 } \\
\text { (Iron (II) Sulfate) }\end{array}$ & 82.74 & 38.19 & 7.09 & 9.25 \\
\hline 5 & BWB/CL-2 (Alum) & 80.98 & 56.98 & 36.36 & 21.03 \\
\hline 6 & $\begin{array}{c}\text { BWB/CL-2 } \\
\text { (Calcium Oxide) }\end{array}$ & 79.61 & 53.51 & 23.26 & 9.92 \\
\hline 7 & $\begin{array}{c}\text { CL } \\
\text { (Iron (II) Sulfate) }\end{array}$ & 78.01 & 62.76 & 6.16 & 14.90 \\
\hline 8 & $\begin{array}{c}\text { CL } \\
\text { (Alum) }\end{array}$ & 77.18 & 74.99 & 14.50 & 24.50 \\
\hline 9 & $\begin{array}{c}\text { CL } \\
\text { (Calcium Oxide) }\end{array}$ & 76.83 & 85.29 & 9.94 & 22.47 \\
\hline
\end{tabular}

\section{CONCLUSION}

Dyeing of cotton fibers using natural dyes from Brazilwood bark and Curcuma longa bulbs extract as well as a combination of both has been done in this study. The results showed that the five dyes extracts had optimum absorption at wavelength $538.57 \mathrm{~nm}$ (BWB); 538.50nm (BWB/CL-1); 538.49nm (BWB/CL2); 440.30nm (BWB/CL-3); and 383.19nm (CL-5) which have confirmed the presence of brazilin at BWB; combinations of brazilin and curcumin at BWB/CL-1, BWB/CL-2, BWB/CL-3; and curcumin on CL. Increased levels of curcumin in blended dyes have induced hypsochromic with a color intensity that also decreased although not significantly. Increased levels of the curcumin have caused an increase in L*, decrease $a^{*}$ and increase $b^{*}$ value on the CieLab coordinates. Meanwhile, the dyeing with different fixers has resulted in the shades variations, which are brown from the BWB/CL-2 dyeing with iron (II) sulfate fixation, dark orange with alum and purple with calcium oxide fixation. This is induced by the presence of specific chromophores and auxochromes in each fixer. The use of iron (II) sulfate fixer has resulted in the highest color intensity compared to the alum and calcium oxide which has the second and third highest color intensity. Besides, the use of calcium oxide fixer has produced the highest $\mathrm{L}^{*}$, while the alum has given the highest $\mathrm{a}^{*}$ and $\mathrm{b}^{*}$ value in the CieLab coordinates.

\section{REFERENCES}

1. A.K. Prusty, A. Trupti Das and N.B. Nayak Das, Journal of Cleaner Production, 18, 1756(2010), DOI: 10.1016/j.jclepro.2010.06.020

2. R. Singh, A. Jain, S. Panwar, D. Gupta, and S.K. Khare, Dyes and Pigments, 66, 102(2005), DOI:10.1016/j.dyepig.2004.09.005

3. P. Ramya, J. Sudisha, N. Lakshmi Devi, S.M. Aradhya, Journal of Medicinal Plants Research, 5, 705(2011), DOI:10.3923/rjpm.2011.695.705

4. R.P. Singh and D.A. Jain, International Journal of Pharmaceutical and Life Sciences, 3, 1376(2012)

5. R.M. Selvam, G. Athinarayanan, A.U. Nanthini, A.J.A.R. Singh, K. Kalirajan, and P.M. Selvakumar, Industrial Crops and Products, 8, 90(2015), DOI:10.22159/ijpps.2016v8i10.12960

6. G.A. Ayoola, H.A.B. Coker, S.A. Adesegun, A.A. Adepoju-Bello, K. Obaweya, and E.C. Ezennia, Tropical Journal of Pharmaceutical Research, 7, 1024 (2008), DOI:10.17179/excli2015-689

7. H.A. Edeoga, D.E. Okwu, and B.O. Mbaebie, African Journal of Biotechnology, 4, 688(2005), DOI: 10.5897/AJB2005.000-3127

8. F. Karc, N. Sener, M. Yamac, I. Sener, and A. Demircah, Dyes and Pigments, 80, 52(2009), DOI:10.1016/j.dyepig.2008.05.001 
RASĀYAN J. Chem.

Vol. 13 | No. 2 |991 - 999| April - June | 2020

9. N. Kusumawati, T. Koestiari, and A.B. Santoso, Research Journal of Pharmaceautical, Biological and Chemical Sciences, 7, 63(2015)

10. J. Sheeja, K. Sampath, R. Manivel, Rasayan Journal of Chemistry, 12(1), 262(2019), DOI: $10.31788 /$ RJC.2019.1215002

11. T.P. Kasih, M.A. Faghlefi, R. Radjagukguk, R.D.J. Murphiyanto, Rasayan Journal of Chemistry, 12(3), 1375(2019), DOI: 10.31788/RJC.2019.1235366

12. M. Joshi, S.W. Ali, R. Purwar, and S. Rajendran, Indian Journal of Fibre \& Textile Research, 34, 304(2009)

13. A.K. Samanta and P. Agarwal, Indian Journal of Fibre \& Textile Research, 34, 399(2009)

14. N. Kusumawati, A.B. Santoso, M.M. Sianita, and S. Muslim, International Journal on Advanced Science, Engineering, and Information Technology, 7, 884(2017), DOI:10.18517/ijaseit.7.3.1014

15. A. Cerempei, E.I. Mureşan, N. Cimpoeşu, C. Carp-Cărare, and C. Rimbu, Indian Crops and Products, 67, 220(2015), DOI:10.1016/j.indcrop.2015.01.019

16. N. Nasirizadeh, H. Dehghanizadeh, M.E. Yazdanshenas, M.R. Moghadam, and A. Karimi, Indian Crops and Products, 40, 366(2012), DOI:10.1016/j.indcrop.2012.03.035

17. M.M. Kasprzak, A. Erxleben, J. Ochocki, RSC Advances, 76, 45877(2015), DOI:10.1039/C5RA10217K

18. S. Girdthep, J. Sirirak, D. Daranarong, R. Daengngem, and S. Chayabutra, Dyes and Pigments, 157, 39(2018), DOI:10.1016/j.dyepig.2018.04.043

19. TM. Vitorino, Thesis, Departamento de Conservação e Restauro, Faculdade de Ciências e Tecnologia, Lisboa, Portugal, (2012).

20. K. Wongsooksin, S. Rattanaphani, M. Tangsathit-kulchai, V. Rattanaphani and J. Barnard Bremner, Suranaree Journal of Science and Technology, 15, 165(2008), DOI:10.1039/c6ra19653e

21. NP. Nirmal, MS. Rajput, RG. Prasad, and M. Ahmad, Asian Pacific Journal of Tropical Medicine, 8, 30(2015), DOI:10.1016/j.apjtm.2015.05.014

22. N. Kusumawati, L. Mufida and R.A. Annisa, Pewarna alami untuk tekstil, Universitas Negeri Surabaya Press, Surabaya, p. 108,111(2018).

23. M. Mirjalili and L. Karimi, The Scientific World Journal., 9, 56(2013), DOI:10.1155/2013/375352

24. A.H. Cahyana, B. Ardiansah, W.H. Ibrahim, Rasayan Journal of Chemistry, 12, 471(2019), DOI: 10.31788/RJC.2019.1225011

25. S.M. Ghoreishian, L. Maleknia, H. Mirzapour, and M. Norouzi, Fibers and Polymers, 14, 207(2013), DOI: 10.1007/s12221-013-0201-9

26. Y. Zhou, J. Zhang, R. Tang, and J. Zhang, Indian Crops and Products, 64, 232(2015), DOI:10.1016/j.dyepig.2016.11.012

27. G.K. Jayaprakash, L.J.M. Rao and K.K. Sakariah, Journal of Agricultural and Food Chemistry, 50, 3672(2002), DOI: $10.1021 / \mathrm{jf025506a}$

28. S. Boonroeng, K. Srikulkit, J. H. Xin, and L. He, Fibers and Polymers, 16, 2431(2015), DOI: $10.1007 / \mathrm{s} 12221-015-4585-6$

29. F. Fournier, L. Viguerie, S. Balme, J-M. Janot, P. Walter, and M. Jaber, Applied Clay Science, 2,17(2016), DOI:10.3390/ma12030360

30. F. Pozzi, K. J. Berg, I. Fiedler, and F. A Casadio, Journal of Raman Spectroscopy, 45, 12(2014), DOI: $10.1002 /$ jrs. 4483

31. F.E. Prado, M. Hilal, S. Chocobar-Ponce, E. Pagano, M. Rosa, and C. Prado,Chromium and The Plant: A Dangerous Affair?, Elsevier Inc, New York, 149,177(2016).

[RJC-5410/2019] 